\title{
A Comparative Analysis of Business Machine Learning in Making Effective Financial Decisions Using Structural Equation Model (SEM)
}

\author{
A. V. L. N. Sujith ${ }^{\mathbb{D}},{ }^{1}$ Naila Iqbal Qureshi ${ }^{D},{ }^{2}$ Venkata Harshavardhan Reddy Dornadula $(\mathbb{D}),{ }^{3}$ \\ Abinash Rath $\mathbb{D}^{4},{ }^{4}$ Kolla Bhanu Prakash $\mathbb{D}^{5},{ }^{5}$ and Sitesh Kumar Singh $\mathbb{D}^{6}$ \\ ${ }^{1}$ Department of Computer Science and Engineering, Anantha Lakshmi Institute of Technology and Sciences, \\ Ananthapuramu, India \\ ${ }^{2}$ Department of Business Administration, College of Business Administration, Princess Nourah Bint Abdulrahman University, \\ Riyadh, Saudi Arabia \\ ${ }^{3}$ IT \& ITES Department, Startups Mentoring Society, Tirupati, Andhra Pradesh 517501, India \\ ${ }^{4}$ School of Business, The Assam Kaziranga University, Jorhat, India \\ ${ }^{5}$ Department of Computer Science Engineering, K L Deemed to Be University, Green Fields, Vaddeswaram, \\ Guntur District, A.P., India \\ ${ }^{6}$ Department of Civil Engineering, Wollega University, Nekemte, Oromia, Ethiopia
}

Correspondence should be addressed to Sitesh Kumar Singh; sitesh@wollegauniversity.edu.et

Received 28 December 2021; Revised 26 January 2022; Accepted 1 February 2022; Published 23 February 2022

Academic Editor: Rana Muhammad Aadil

Copyright (c) 2022 A. V. L. N. Sujith et al. This is an open access article distributed under the Creative Commons Attribution License, which permits unrestricted use, distribution, and reproduction in any medium, provided the original work is properly cited.

\begin{abstract}
Globally, organisations are focused on deriving more value from the data which has been collected from various sources. The purpose of this research is to examine the key components of machine learning in making efficient financial decisions. The business leaders are now faced with huge volume of data, which needs to be stored, analysed, and retrieved so as to make effective decisions for achieving competitive advantage. Machine learning is considered to be the subset of artificial intelligence which is mainly focused on optimizing the business process with lesser or no human interventions. The ML techniques enable analysing the pattern and recognizing from large data set and provide the necessary information to the management for effective decision making in different areas covering finance, marketing, supply chain, human resources, etc. Machine learning enables extracting the quality patterns and forecasting the data from the data base and fosters growth; the machine learning enables transition from the physical data to electronically stored data, enables enhancing the memory, and supports with financial decision making and other aspects. This study is focused on addressing the application of machine learning in making the effective financial decision making among the companies; the application of ML has emerged as a critical technology which is being applied in the current competitive market, and it has offered more opportunities to the business leaders in leveraging the large volume of data. The study is intended to collect the data from employees, managers, and business leaders in various industries to understand the influence of machine learning in financial decision making .
\end{abstract}

\section{Introduction}

Business leaders around the globe are now using the advanced techniques of machine leaning (ML) and deep learning (DL) as they offer enhanced benefits in decision making. The replication of human intellectual processes by machines, particularly computer systems, is known as artificial intelligence. The approaches and other aspects of artificial intelligence (AI) tend to support in creating better risk management models and estimate the requirement of cash and other aspects based on the historical data. With its immense potential, AI tools like ML are being applied for 
enhanced financial decision making, mainly in stock markets to forecast the price of the securities and enable the management of the risk efficiently [1]. It is estimated that nearly $\$ 41$ billion annually is being spent on AI, mainly in the financial industry for effective decision making.

The critical aspect of $\mathrm{AI}$ is that it is being implemented for algorithmic trading, enables management of the risk, supports in process automation, and manages the cash movement effectively. The most relevant aspect of AI method is focused on machine learning as they offer supporting aspects in forecasting the data and information based on the collated information [2]. Furthermore, ML is used in performing high end statistical modelling and analysis using the data, also supporting in creating better dashboard reports. Also, AI and ML approaches are mainly applied in the front office of major financial institutions, banking, and other sectors so as to provide effective services to the customers. Moreover, they enable assessing the credit quality of the customers and managing the critical reports in an effective manner [3].

With the increased scrutiny by the regulators related to financial transaction, companies are required to collect and maintain the database of the customers for complying antimoney laundering, knowing your customer, and other information. Hence, the banking and financial institutions are holding a large amount of data which needs to be stored and retrieved and reports need to be generated for better decision making $[2,4]$. Moreover, the application of ML based technologies supports in creating better interaction with the customers and enables addressing their queries in an effective manner. The application of machine learning algorithms in discovering better concepts, analysing the data effectively, and providing the information for taking better financial decisions [5]. The ML algorithms usually create customised reports depending on available data, resulting in simple and straightforward information being delivered to various levels of management. Employees and management tend to deploy such technologies for recognising the pattern, focusing on estimating the price of the security and taking adequate steps in managing the risk effectively [4]. One of the critical aspects of AI is the application of natural language processing (NLP). NLP is a field of artificial intelligence (AI) that provides computers the capacity to read text and spoken language in a manner similar to that of humans which supports in analysing the data, offers more potential in integrating the large volume of information, supports in predicting the pattern, and extrapolates the information for effective analysis on the broader market [6]. Machine learning can be applied to various financial decision making for the management as it enables making extensive analysis covering regression, vector machines, etc. These aspects support in understanding the pattern based on the available data and classifies the information in order to make quick and better decisions. The management can also enable forecasting the prices of the securities and predict the bullish or bearish phase in the security price or the broader market index.

Based on the increased demand in delivering high end customer services, banks and financial institutions have intended to apply novel AI and ML methods to cater to the needs of the customers. The implementation of the ML approaches supports in reducing the cost, optimizing the overall productivity, supports in risk management, and engages the customers effectively for enhanced financial decision making. Furthermore, the ML algorithms tend to offer customised reports based on the available data and thereby clear and concise information is being provided to the different level of management so as to ensure organised decision making.

The development of different technological advancements in the financial industry has enabled the creation of specific data sets and also reduced the investment in IT infrastructure as they can save more information through cloud computing. Hence, this study is focused on analysing the critical factors of machine learning in effective financial decision making; the major factors considered are the usage of ML in risk management, identification of areas of financial performance, and managing the cash and other resources effectively. These are highly critical financial decision making and hence the study is revolved around these factors.

\section{Review of Literature}

Thematic modelling is the application of ML to NLP; therefore we supplement our study with a symbiotic element using ML techniques to understand ML research in finance [7]. As far as we know, ML's ability in financial decision making was examined for the first time from a research perspective, with emphasis on neural networks as a tool for economic decision making. In the 2010s, the Journal of Banking \& Finance also published a series of preliminary studies reflecting the future benefits for the banking sector, examining whether ML can improve lending decisions and credit risk management [8]. The researchers used neural networks to rank Italian companies based on the probability of financial difficulties, but applied genetic learning algorithms to the same subject. New research in financial journals continued to focus on forecasting, but switched to deep learning techniques and other advanced ML techniques. These latest apps include understanding default recovery speeds, learning the coverage rates for the best options, and modelling of the investment environment.

Artificial intelligence and machine learning can be used to manage risks through earlier, more accurate risk assessments. ML is extremely beneficial to the organisation in making improved risk management decisions, and the second biggest relationship is discovered in efficiently managing the organisation's cash. For example, if artificial intelligence and machine learning allow decisions to be made based on past relationships between the values of different assets, financial institutions will be better able to manage these risks [9]. Tools to reduce driving risks can be particularly beneficial for the entire system. [5]. In addition, artificial intelligence and machine learning can be used to predict and detect the risk of fraud, suspicious transactions, late payments, and cyber-attacks, which can lead to better risk management. But tools based on artificial intelligence 
and machine learning can also omit new types of dangers and events, as they can potentially "over-educate" previous events [10]. While artificial intelligence and machine learning tools can improve risk management, the latest developments in these strategies mean that they have not yet been tested to manage risks in changing economic conditions. This research article is organised as follows: Section 1 describes the introduction, and Section 2 describes the literature work. The methodology is described in Section 3. Section 4 summarizes the outcomes and research findings, and Section 5 concludes with a conclusion and future scope. The use of artificial intelligence and machine learning creates risk "black boxes" in decision making that can cause complex problems, especially at the end of events. It can be difficult for financial users-and regulators in particular-to understand how decisions such as those relating to trade and investment were made. Artificial intelligence and machine learning are problematic not just because of the lack of clarity, but also because of potential biases acquired by the techniques from human preconceptions and collecting artefacts buried in the training data, which may result in unfair or incorrect choices. In addition, the communication mechanism used by these tools may be incomprehensible to humans, which causes monitoring problems for human operators of such solutions [11]. When in doubt, users of these artificial intelligence and machine learning tools can simultaneously pull their "shut-off switches," that is, turn off the systems manually. Following such incidents, users can only reactivate the systems if other users in the market do so in a coordinated manner. This can increase system-wide voltage risks and the need for proper switches.

Artificial intelligence and machine learning can facilitate "more personal" and "more personal" financial services through big data analytics [12]. For example, artificial intelligence and machine learning can facilitate big data analysis, thereby clarifying the characteristics of individual consumers and / or investors and allowing companies to design welltargeted services. However, the use of consumer data can lead to privacy and information security issues. In addition, since analytical artificial intelligence and machine learning data can analyse the characteristics of individual customers through public data, it would be necessary to consider customer results. It must be protected while protecting the anonymity of individual consumers and facilitating the safe and efficient use of big data for better services [13]. Deep learning algorithms, in particular, offer benefits for organisational decision making, such as supporting employees with information processing, so augmenting their analytical capacities and maybe assisting them in transitioning to more design output. In addition, in order to protect consumers and investors, it would be important to establish well-designed governance structures for financial service providers using artificial intelligence and machine learning.

\section{Methodology}

The purpose of the article is to explore the significance of machine learning approaches in supporting the financial decision making of the organisation. For the purpose of the study the researchers have considered the selection of private banking companies and financial institutions in India and the data are collated from the respondents. Machine learning algorithms play a crucial role in finance to identify fraud, simplify trading processes, and give financial advice to clients. Without being explicitly taught, machine learning can examine lots of data sets in a short period of time to improve results [14]. The researchers have focused on using the descriptive research design as the area of application of machine learning in financial decision making is gaining importance in the emerging economies. Moreover, business leaders are looking to implement new technologies so that they can effectively manage the risk, optimise the cash inflows and outflows, support in better pricing of the securities, and apprehend the areas to generate better financial returns [15].

The data are collected through the questionnaire from the respondents, nonprobability sampling methods were applied, and the researchers have generated only 229 completed data from the sample population and hence all were considered for performing the analysis [16]. Using closed ended questionnaire enables the researchers to get the responses from the sample population in an effective manner; in order to convert the overall responses into quantitative aspect, the Likert scale principle is applied [1: strongly disagree and 5: strongly agree]. The authors intend to test the data using basic descriptive analysis of the demographic variables, and then apply AMOS for implementing the structural equation model (SEM) [17]. The SEM model enables measuring the overall association of the independent variables towards the dependent variables.

\section{Hypothesis}

Ho: there is no significant association between the application of machine learning in risk management and effective financial decision making in the organisation.

Ho: there is no significant association between the application of machine learning in analysing the area of enhancing financial performance and effective financial decision making in the organisation.

Ho: there is no significant association between the cash management and effective financial decision making in the organisation.

3.1. Analysis. This section provides detailed analysis based on the data collected by the authors; the major analysis includes percentage analysis, correlation analysis, and SEM model analysis.

From Table 1, the analysis reveals that $86 \%$ of the sample population were male and the remaining were female, also $30.6 \%$ of the respondents were in the age group of 31-40 years, $28.8 \%$ were in the age group of less than 30 years, $27.5 \%$ were above 50 years and remaining were in the age group between $41-50$ years. $52 \%$ of them were living in the joint family, $61.6 \%$ were working in banking companies, and the remaining $38.4 \%$ were working in financial and 
TABLE 1: Demographic analysis.

\begin{tabular}{|c|c|c|c|}
\hline Demographic variables & Features & Frequency & Percent \\
\hline \multirow{2}{*}{ Gender category } & Male & 197 & 86.00 \\
\hline & Female & 32 & 14.00 \\
\hline \multirow{4}{*}{ Age category } & Less than 30 years & 66 & 28.80 \\
\hline & $31-40$ years & 70 & 30.60 \\
\hline & $41-50$ years & 30 & 13.10 \\
\hline & Above 50 years & 63 & 27.50 \\
\hline \multirow{2}{*}{ Type of family currently living } & Joint family & 119 & 52.00 \\
\hline & Nuclear family & 110 & 48.00 \\
\hline \multirow{2}{*}{ Nature of industry } & Banking companies & 141 & 61.60 \\
\hline & Financial and nonbanking companies & 88 & 38.40 \\
\hline \multirow{3}{*}{ Management cadre } & Lower level management & 62 & 27.10 \\
\hline & Middle level management & 134 & 58.50 \\
\hline & Process head & 33 & 14.40 \\
\hline \multirow{5}{*}{ Total experience } & Less than 3 years of experience & 60 & 26.20 \\
\hline & $4-8$ years & 54 & 23.60 \\
\hline & $8-12$ years & 32 & 14.00 \\
\hline & $12-16$ years & 19 & 8.30 \\
\hline & Above 16 years & 64 & 27.90 \\
\hline
\end{tabular}

nonbanking corporations. $58.5 \%$ were in the middle level management, $27.10 \%$ were junior level management, and the remaining were working as process head in the current organisation. $26.2 \%$ possess experience of less than 3 years, $23.6 \%$ were possessing experience between $4-8$ years, and $14 \%$ were having experience of 8-12 years.

The researcher intends to analyse the role of machine learning in offering more opportunities for the management in taking more decisions [18]. Based on Table 2, it is noted that $41.5 \%$ of the respondents have strongly agreed that the machine learning tends to provide more opportunities for the management in taking better decision; also $31.9 \%$ of the respondents have agreed to the statement; however, $13.5 \%$ of the respondents have been neutral, $7.9 \%$ of the respondents have disagreed, and $5.2 \%$ of the respondents have strongly disagreed to the statement. Figure 1 introduces a chart that represents the opportunities possessed by machine learning. Machine learning is useful because compute is plentiful and inexpensive. The volume of data we are gathering, as well as development in capabilities of machine learning algorithms, has been driven by abundant and low-cost computation.

The authors have also tested the respondents to understand whether the application of machine learning supports in managing the overall operational costs. From Table 3, it is identified that $39.3 \%$ of the respondents have strongly agreed to the statement, and $30.1 \%$ of the respondents have agreed to the same. Meanwhile, $15.7 \%$ of the respondents have been neutral, $9.6 \%$ of them have disagreed, and $5.2 \%$ of the respondents have strongly disagreed. Support of machine learning in managing the cost effectiveness is shown in Figure 2. This figure represents a chart which is based on different respondents values; these values have measured through strongly disagree, disagree, neutral, agree, and strongly agree.

3.2. Correlation. The correlation analysis is one of the useful statistical tools to measure the overall association between
TABLE 2: Machine learning possesses more opportunities.

\begin{tabular}{lcc}
\hline More opportunities & Frequency & Percent \\
\hline Strongly disagree & 12 & 5.2 \\
Disagree & 18 & 7.9 \\
Neutral & 31 & 13.5 \\
Agree & 73 & 31.9 \\
Strongly agree & 95 & 41.5 \\
Total & 229 & 100 \\
\hline
\end{tabular}

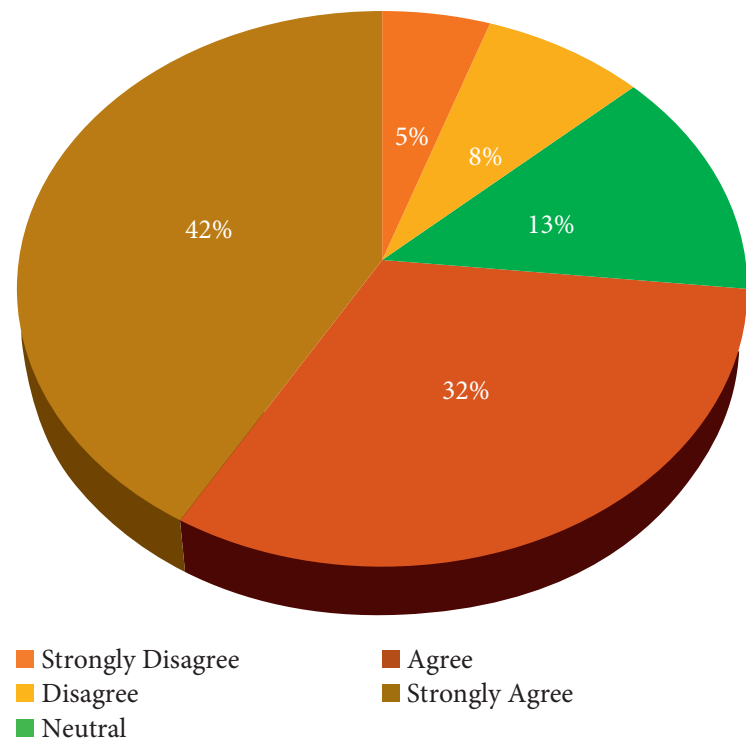

FIGURE 1: Chart representing that machine learning possesses more opportunities.

the variables; in the study the researchers have considered three key independent variables, viz., risk management, areas of enhancing financial performance, and managing the cash, and its relationship towards the dependent variable enhances financial decision making. 
TABLE 3: Machine learning supports in managing the cost effectively.

\begin{tabular}{lcc}
\hline Cost management & Frequency & Percent \\
\hline Strongly disagree & 12 & 5.2 \\
Disagree & 22 & 9.6 \\
Neutral & 36 & 15.7 \\
Agree & 69 & 30.1 \\
Strongly agree & 90 & 39.3 \\
Total & 229 & 100 \\
\hline
\end{tabular}

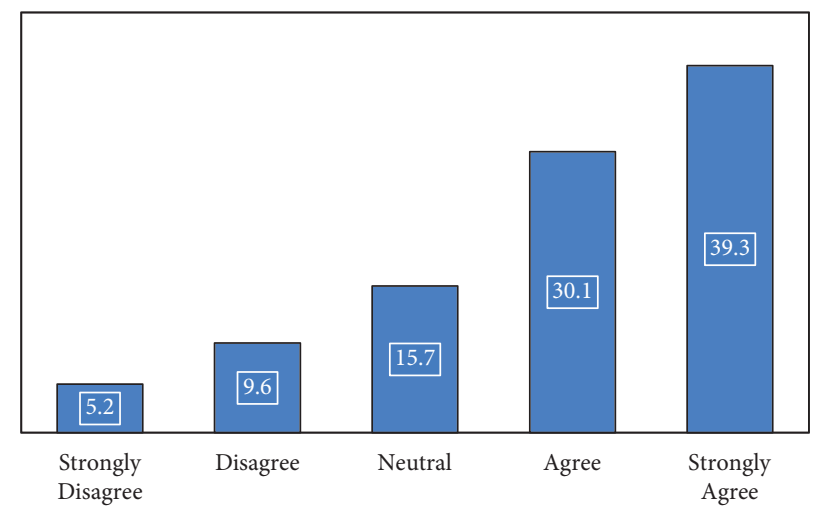

FIGURE 2: Chart representing the machine learning supports in managing the cost effectively.

TABLE 4: Correlation analysis.

\begin{tabular}{|c|c|c|c|c|}
\hline & $\begin{array}{c}\text { Risk } \\
\text { management }\end{array}$ & $\begin{array}{l}\text { Areas of financial } \\
\text { performance }\end{array}$ & $\begin{array}{l}\text { Managing cash } \\
\text { effectively }\end{array}$ & $\begin{array}{l}\text { ML in financial decision } \\
\text { making }\end{array}$ \\
\hline Risk management & 1 & $0.660^{* *}$ & $0.891^{* *}$ & $0.927^{* *}$ \\
\hline Areas of financial performance & $0.660^{* *}$ & 1 & $0.745^{* *}$ & $0.724^{* *}$ \\
\hline Managing cash effectively & $0.891^{* *}$ & $0.745^{* *}$ & 1 & $0.894^{* *}$ \\
\hline ML in financial decision making & $0.927^{* *}$ & $0.724^{* *}$ & $0.894^{* *}$ & 1 \\
\hline
\end{tabular}

Based on table of the correlation analysis shown in Table 4 , it is identified that the variables possess higher positive association as the values are more than +0.700 , higher correlation is identified between financial decision making and risk management; hence ML is highly helpful for the organisation in taking improvised decision making related to risk management; also the next highest association is noted between managing the cash of the organisation effectively. Businesses get cash inflows through sales and other aspects, which are to be utilised effectively so that the cost is minimised so that the profits can be maximized; hence machine learning technologies support in making quick decisions.

3.3. Structural Equation Modelling Approach (SEM). The SEM is considered as an exhaustive multivariate approach which enables the researcher to use the combination of factor analysis and regression analysis; moreover it is used to assess the overall structural association between the measured variables and the constructs [19]. Hence, this model is highly supported by the scholars and practitioners as it estimates the multiple and other dependence through the analysis; furthermore, the analysis can consider both endogenous and exogenous variables. This has been shown in Figure 3.

From Table 5 of the analysis, it is noted that the $P$ value of all the independent variables towards the financial decision making is less than $5 \%$ level of significance (value is at 0.05 ); hence the null hypothesis is rejected and alternate hypothesis is accepted.

Therefore, the statement of hypothesis is stated as Table 6.

\section{Findings and Discussion}

Therefore, for the overall analysis, it can be stated that the key independent variables like risk management and analysing the area to enhance financial performance and cash management using machine learning are highly helpful in making quick financial decisions. Business leaders are highly poised to focus on critical areas where they can enhance the business profits, managing the risk is a key attribute, and implementation of machine learning tools and techniques can forecast the outcomes; thereby appropriate financial decision making can be made by the leaders for maximising the profits [20]. Furthermore other areas like the operational cost and expenses can be analysed so that they can be reduced using different strategies, 


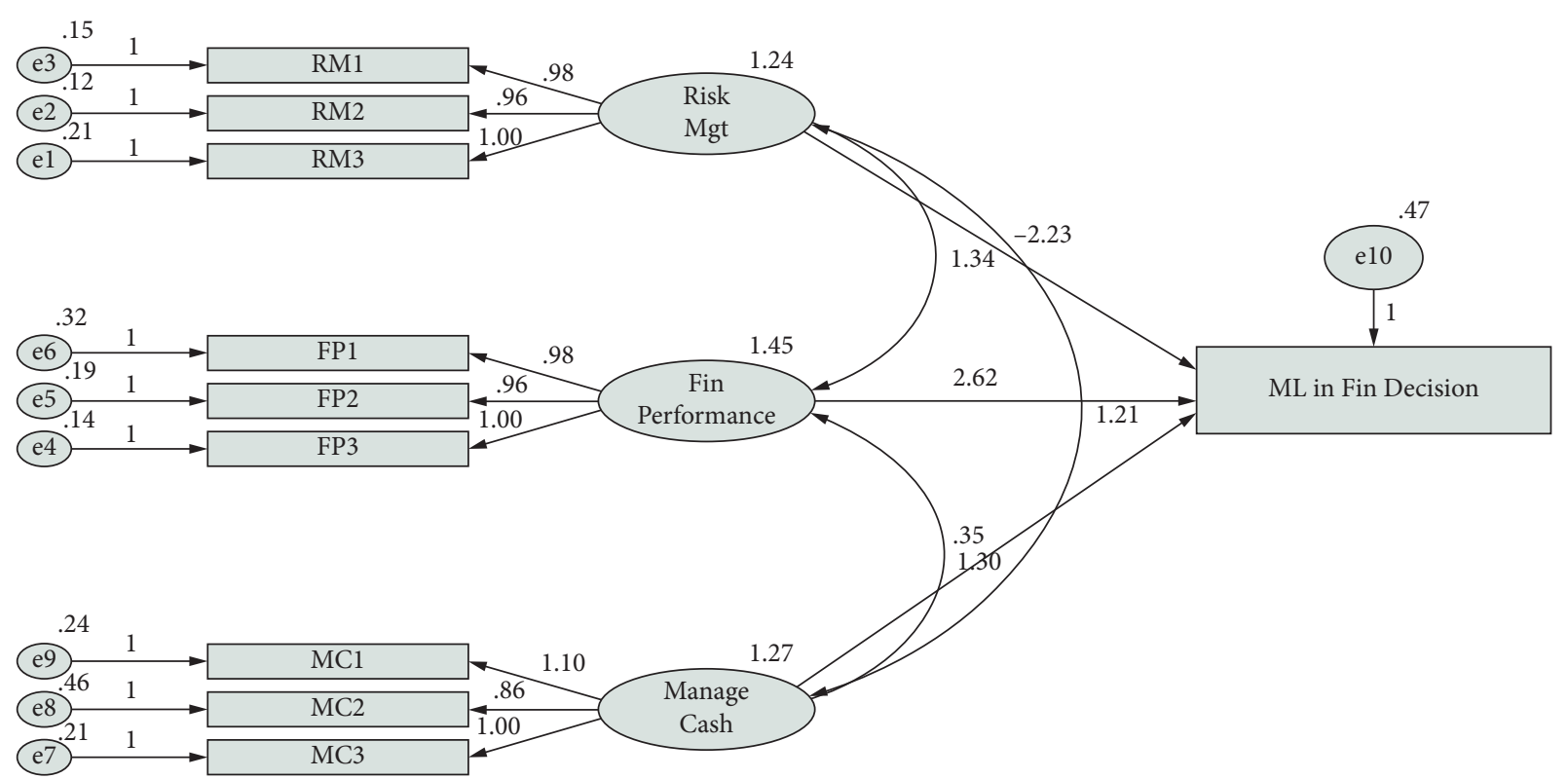

FIGURE 3: Chart representing the SEM between the independent and dependent variables.

TABLE 5: Regression weights.

\begin{tabular}{|c|c|c|c|c|c|}
\hline Dependent variable & Independent variable & Estimate & S.E. & C.R. & $P$ \\
\hline Financial decision & Risk_Mgt & -2.228 & 5.745 & -0.388 & $\leq 0.001$ \\
\hline Financial decision & Fin_Performance & 2.618 & 4.503 & 0.581 & $\leq 0.001$ \\
\hline Financial decision & Manage_Cash & 0.353 & 0.96 & 0.368 & $\leq 0.001$ \\
\hline
\end{tabular}

TABLE 6: Hypothesis analysis.

Hypothesis

Decision

There is a significant association between the application of machine learning in risk management and effective financial decision making in the organisation

There is a significant association between the application of machine learning in analysing the area of enhancing financial performance and effective financial decision making in the organisation

There is a significant association between the cash management and effective financial decision making in the organisation

Accept

Accept

Accept

also the managers understand that cash is one of the critical factors in production and hence it needs to be managed effectively. Using machine learning models, the management can forecast the requirement of cash so that better decision can be made.

\section{Conclusion}

Machine learning is seen as a subset of artificial intelligence that mainly focuses on optimizing business processes with little or no human intervention. ML technologies allow the model to be analysed and identified from a large set of data and provide management with the information they need to make effective decisions in several areas of finance, marketing, and supply chain. A key aspect of artificial intelligence is that it applies algorithmic transactions, can manage risks, supports process automation, and efficiently manages cash flow. The most relevant aspect of the AI method focuses on machine learning as it provides support aspects for predicting data and information based on the information collected. In addition, the use of ML-based technology helps to better interact with customers and answer their questions effectively. Use machine learning algorithms to discover better concepts, provide efficient data analysis, and provide the information you need to make better financial decisions. Employees and management tend to develop such techniques to recognize the pattern, focus on the valuation of securities, and take appropriate measures to effectively manage risks. Using ML methods helps reduce costs, optimise overall productivity, support risk management, and engage customers to make better financial decisions. In addition, ML algorithms tend to generate personal reports based on available data, providing clear and concise information at various levels of management for organised decision making.

\section{Data Availability}

The data shall be made available on request. 


\section{Conflicts of Interest}

The authors declare that they have no conflicts of interest.

\section{References}

[1] S. Mullainathan and J. Spiess, "Machine learning: an applied econometric approach," The Journal of Economic Perspectives, vol. 31, no. 2, pp. 87-106, 2017.

[2] A. Mishra, D. Irwin, P. Shenoy, J. Kurose, and T. Zhu, "Smartcharge: cutting the electricity bill in smart homes with energy storage," in Proceedings of the 3rd International Conference on Future Energy Systems: Where Energy, Computing and Communication Meet, p. 29, ACM, Madrid, Spain, May 2012.

[3] R. Ghasemiyeh, R. Moghdani, and S. S. Sana, "A hybrid artificial neural network with metaheuristic algorithms for predicting stock price," Cybernetics \& Systems, vol. 48, no. 4, pp. 365-392, 2017.

[4] M. Kampouridis and F. E. B. Otero, "Heuristic procedures for improving thepredictability of a genetic programming financial forecasting algorithm," Soft Computing, vol. 21, no. 2, pp. 295-310, 2017.

[5] C. Worasucheep, "Forecasting currency exchange rates with an Artificial Bee Colony-optimized neural network," in Proceedings of the 2015 IEEE Congress on Evolutionary Computation (CEC), pp. 3319-3326, IEEE, Sendai, Japan, May 2015.

[6] A. J. Hussain, D. Al-Jumeily, H. Al-Askar, and N. Radi, "Regularized dynamic self-organized neural network inspired by the immune algorithm for financial time series prediction," Neurocomputing, vol. 188, pp. 23-30, 2016.

[7] S. Kumar, P. K. Baag, and K. V. Shaji, "Impact of ESG integration on equity performance between developed and developing economy: evidence from S and P 500 and NIFTY 50," Empirical Economics Letters, vol. 20, no. 4, pp. 01-16, 2021.

[8] B. Weng, L. Lu, X. Wang, F. M. Megahed, and W. Martinez, "Predicting short-term stock prices using ensemble methods and online data sources," Expert Systems with Applications, vol. 112, pp. 258-273, 2018.

[9] S. Sanober, I. Alam, S. Pande et al., "An enhanced secure deep learning algorithm for fraud detection in wireless communication," in Wireless Communications and Mobile Computing, V. Shanmuganathan, Ed., vol. 2021, Hindawi Limited, Article ID 6079582, 14 pages, Hindawi Limited, 2021.

[10] V. Panwar, D. K. Sharma, K. V. P. Kumar, A. Jain, and C. Thakar, "Experimental investigations and optimization of surface roughness in turning of EN 36 alloy steel using response surface methodology and genetic algorithm," Materials Today Proceedings, vol. 46, 2021.

[11] A. Piepenbrink and E. Nurmammadov, "Topics in the literature of transition economies and emerging markets," Scientometrics, vol. 102, no. 3, pp. 2107-2130, 2015.

[12] S. Oprea, "Informatics solutions for electricity consumption optimization," in Proceedings of the 2015 16th IEEE International Symposium on Computational Intelligence and Informatics (CINTI), pp. 193-198, IEEE, Budapest, Hungary, November 2015.

[13] A. Jain and A. K. Pandey, "Multiple quality optimizations in electrical discharge drilling of mild steel," Sheet" Material Today Proceedings, vol. 8, pp. 7252-7261, 2019.

[14] A. Jain, A. K. Yadav, and Y. Shrivastava, "Modelling and optimization of different quality characteristics in electric discharge drilling of titanium alloy sheet" Material," Today Proceedings, vol. 21, pp. 1680-1684, 2019.

[15] A. Jain and A. Kumar Pandey, "Modeling and optimizing of different quality characteristics in electrical discharge drilling of titanium alloy (Grade-5) sheet," Materials Today Proceedings, vol. 18, pp. 182-191, 2019.

[16] S. Kumar, "Effective hedging strategy for us treasury bond portfolio using principal component analysis," Academy of Accounting and Financial Studies Journal, vol. 26, no. 2, pp. 1-17, 2022.

[17] K. Mahajan, U. Garg, and M. Shabaz, "CPIDM: a clusteringbased profound iterating deep learning model for HSI segmentation," in Wireless Communications and Mobile Computing, V. Shanmuganathan, Ed., vol. 2021, Hindawi Limited, Article ID 7279260, 12 pages, Hindawi Limited, 2021.

[18] D. S. Ushakov, V. V. Shepelev, and Y. O. Patlasov, "Marketing researches of the modified starch market and the technologies of its production," IOP Conference Series: Earth and Environmental Science, vol. 422, no. 1, Article ID 012128, 2020.

[19] W. Xu, Z. Zhang, D. Gong, and X. Guan, "Neural network model for the risk prediction in cold chain logistics," International Journal of Multimedia and Ubiquitous Engineering, vol. 9, no. 8, pp. 111-124, 2014.

[20] S. Tirunillai and G. J. Tellis, "Mining marketing meaning from online chatter: strategic brand analysis of big data using latent dirichlet allocation," Journal of Marketing Research, vol. 51, no. 4, pp. 463-479, 2014 